\title{
Synthesis of some bis-triazole derivatives as probes for cytotoxicity study
}

\author{
Mohammad Al-Amin and M. Rabiul Islam
}

Department of Chemistry, Jahangirnagar University, Savar, Dhaka 1342, Bangladesh.

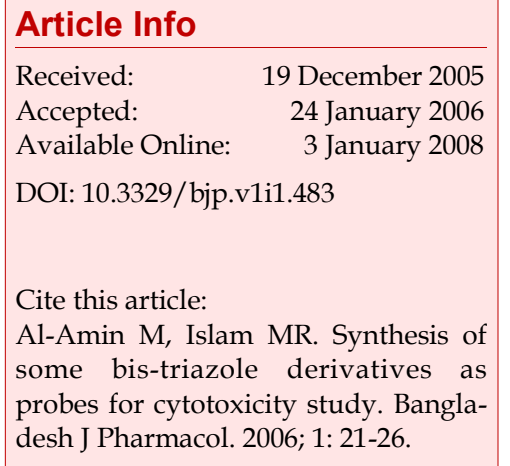

\section{Abstract}

A series of bis-[4-N-amino-5-mercapto-1,2,4-triazol-3-yl] alkanes (1a-e) and their Schiff bases with 2-adamanta-none (2a-d) and bis - [1, 2, 4-triazolo [3, 4b] - 1, 3, 4-thiadiazol-4-yl] alkanes (3a-e) have been synthesized with high yields. The cytotoxicity study of these newly synthesized compounds against brine shrimp lethality test as well as Structure activity relationship (SAR) has been discussed.

\section{Introduction}

Triazoles are five membered heterocyclic compounds having three nitrogen atoms. They are of two types:

If two triazole units are linked by carbon atoms, then they form bis-triazole. Various 1,2,4-triazols are found to be linked with diverse pharmacological activities (Hirota et al., 1991; Yale and Piala, 1966; Andotra and Sharma, 1988). The 1,2,4-triazol nucleus has been incorporated into a wide variety of therapeutically interesting drug candidates including $\mathrm{H}_{1} / \mathrm{H}_{2}$ histamine receptor blockers, cholinesterase active agents, CNS stimulants, anti-anxiety agents and sedative (Heindel and Reid, 1980). It was also found that the thiadiazoline nucleus which incorporates a toxophoric N-C-S linkage exhibits a large number of biological activities. A number of 1,3,4-thiadiazoline possessed antibacterial properties comparable with sulphonamide drugs (Omar and Aboul-Wafa, 1986). Subsequently, thiadiazole derivatives have found applications as antitumour agents, pesticides, dyes, lubricants and analytical reagents (Lubrizol Corp, 1981).
Encouraged by the varied biological activities of 1,2,4triazoles and in continuation of our work on the synthesis of N-bridged heterocycles derived from bistriazoles (Holla et al., 1988), a series of bis-[4-N-amino-5

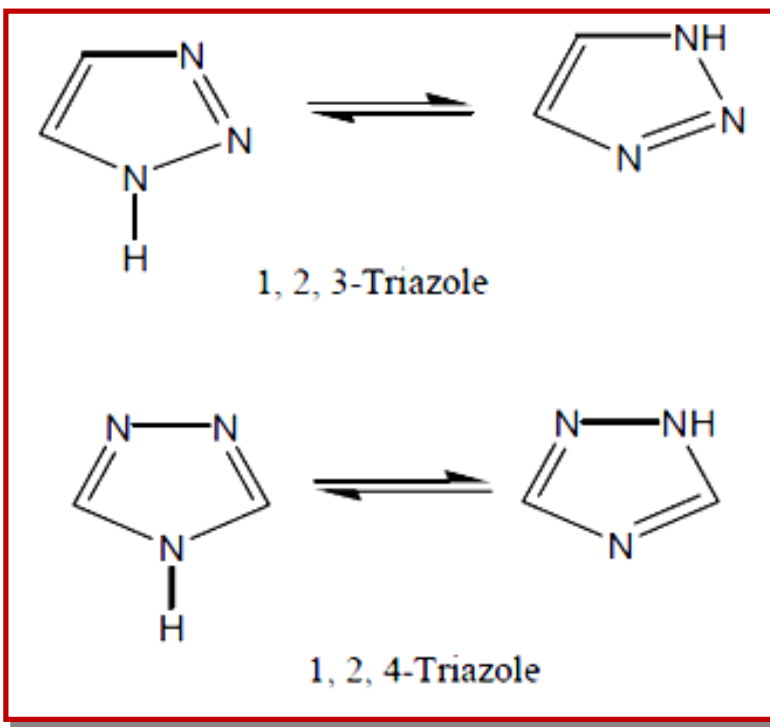




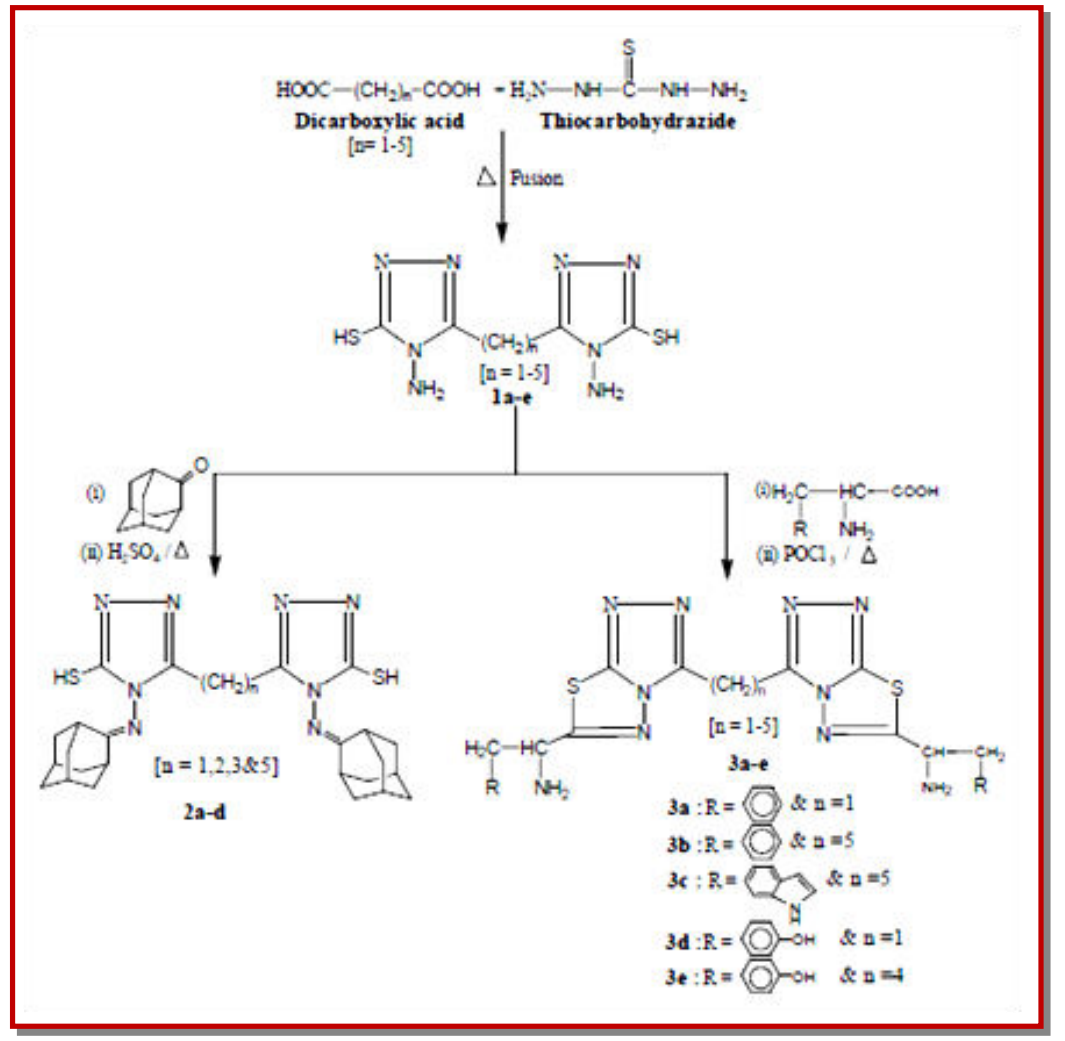

Scheme 1

-mercaptotriazol-3-yl] alkanes were synthesized and their schiff bases were prepared by condensing them with 2-adamantanone in DMF-ethanol in the presence of concentrated $\mathrm{H}_{2} \mathrm{SO}_{4}$. Further, the some of the bistriazoles were cyclised with various amino acids using phosphorous oxychloride $\left(\mathrm{POCl}_{3}\right)$ (Scheme 1$)$. All of these newly synthesized compounds were characterized with the help of spectral data analysis and all of the synthesized compounds were screened for their cytotoxicity properties by brine shrimp lethality bioassay (Meyer et al., 1982).

The obligatory bis-[4-N-amino-5-mercapto-1, 2, 4-triazol -3-yl] alkanes, 1a-e were synthesized by the direct fusion of dicarboxylic acids $(n=1-5)$ with thiocarbohydrazide (Scheme 1). Then these bis-triazolylalkanes, 1ae were converted into their respective Schiff bases, $2 \mathbf{a}-\mathbf{d}$ by condensing them with 2-adamantanone in the presence of few drops of concentrated sulfuric acid. Finally, the cyclisation of bis-triazolylalakanes with various amino acids using phosphorous oxychloride afforded bis-[1,2,4-triazolo [3,4-b]-1,3,4-thiadiazol-4-yl] alkanes, 3a-e. The structures of compounds 1a-e, 2a-d and 3a-e were confirmed on the basis of IR, ${ }^{1} \mathrm{H}-\mathrm{NMR}$ and ${ }^{13} \mathrm{C}-\mathrm{NMR}$ spectral data analysis.

\section{Materials and Methods}

All melting points were recorded by thin disk method on a "Fischer Johns" electrothermal melting point apparatus and are not corrected. Infrared spectra were recorded on DR-8001, SHI-MADZU FT-IR spectrophotometer as a solid which was finely grounded in a small agate mortar with a drop of nujol (liquid hydrocarbon) as a mull and also in $\mathrm{KBr}$ disk. ${ }^{1} \mathrm{H}-\mathrm{NMR}$ spectra were measured by WP 400-NMR spectrometer, deuterated solvents such as dimethyl sulfoxide (DMSO- $\left.\mathrm{d}_{6}\right)$, methanol $\left(\mathrm{CD}_{3} \mathrm{OD}\right)$ and also chloroform $\left(\mathrm{CDCl}_{3}\right)$ were used as solvents and the chemical shifts were quoted as $\delta$-value relative to tetramethyl silane (TMS, $\delta=0$ ) as an internal standard. The ${ }^{13} \mathrm{C}-\mathrm{NMR}$ spectra were measured by WP 50 NMR spectrometer. The purity of compounds was checked by TLC on silica gel plates and iodine was used as a visualizing agent.

Bis-(4-N-amino-5-mercapto-1,2,4-triazol-3-yl) alkanes, 1a-e

A mixture of dicarboxylic acids (malonic acid, succinic acid, gluteric acid, adipic acid, palmilic acid) and thiocarbohydrazide in the ratio of 1:2 contained in a 100 $\mathrm{mL}$. round-bottom flask was heated in an oil bath until 
Table I

Physical and spectral data of compounds

\begin{tabular}{|c|c|c|c|c|c|}
\hline $\begin{array}{l}\text { Com- } \\
\text { pounds }\end{array}$ & $\mathrm{n}$ & $\begin{array}{c}\text { Yield } \\
(\%)\end{array}$ & $\begin{array}{l}\text { m.p. } \\
\left({ }^{\circ} \mathrm{C}\right)\end{array}$ & Nature of compounds & $\operatorname{IR}\left(\mathrm{cm}^{-1}\right)$ \\
\hline $1-\mathrm{a}$ & 1 & 80 & $240-245$ & White crystal & $\begin{array}{l}3315 \& 3298(\mathrm{vN}-\mathrm{H}), 2926 \& 2855 \\
\text { (vC-H,aliphatic),2359(vS-H),1600 (vC=N). }\end{array}$ \\
\hline $1-b$ & 2 & 85 & $280-282$ & $\begin{array}{l}\text { White } \\
\text { crystalline solid }\end{array}$ & $\begin{array}{l}\text { 3315\&3155(vN-H),2924 \& 2855(vC-H, aliphatic),2361(vS- } \\
\text { H),1595 (vC=N). }\end{array}$ \\
\hline $1-\mathrm{c}$ & 3 & 75 & $240-242$ & $\begin{array}{l}\text { White } \\
\text { crystalline solid }\end{array}$ & $\begin{array}{l}3310 \& 3295(\mathrm{vN}-\mathrm{H}), 2925 \& 2855(\mathrm{vC}-\mathrm{H} \text {, aliphatic),2359(vS- } \\
\mathrm{H}), 1598(\mathrm{vC}=\mathrm{N}) \text {. }\end{array}$ \\
\hline $1-\mathrm{d}$ & 4 & 80 & $250-252$ & $\begin{array}{l}\text { White } \\
\text { crystalline solid }\end{array}$ & $\begin{array}{l}3325 \& 3285(\mathrm{vN}-\mathrm{H}), 2924 \& 2855 \\
\text { (vC-H,aliphatic),2361(vS-H),1590 (vC=N). }\end{array}$ \\
\hline 1-e & 5 & 78 & $215-217$ & $\begin{array}{l}\text { White } \\
\text { crystalline solid }\end{array}$ & $\begin{array}{l}\text { 3244\&3200(vN-H), 2928\& } 2856 \\
\text { (vC-H,aliphatic),2360(vS-H),1600 (vC=N). }\end{array}$ \\
\hline $2-\mathrm{a}$ & 1 & 60 & $265-270$ & $\begin{array}{l}\text { White } \\
\text { crystalline solid }\end{array}$ & 2926\&2855(vC-H,aliphatic),2359 (vS-H),1608(vC=N). \\
\hline $2-b$ & 2 & 65 & $255-257$ & $\begin{array}{l}\text { White } \\
\text { crystalline solid }\end{array}$ & 2924\&2855(vC-H,aliphatic),2359 (vS-H),1635(vC=N). \\
\hline $2-\mathrm{c}$ & 3 & 75 & $208-210$ & $\begin{array}{l}\text { White } \\
\text { crystalline solid }\end{array}$ & 2926\&2855(vC-H,aliphatic),2359 (vS-H),1608(vC=N). \\
\hline $2-d$ & 5 & 79 & $235-237$ & $\begin{array}{l}\text { White } \\
\text { crystalline solid }\end{array}$ & 2928\&2853(vC-H,aliphatic),2361 (vS-H), 1615(vC=N). \\
\hline $3-\mathrm{a}$ & 1 & 60 & $210-215$ & Gray crystalline solid & $\begin{array}{l}\text { 3315(vN-H),3100(vC-H,aromatic), 2924\&2855(vC- } \\
\text { H,aliphatic), } 1593(\mathrm{vC}=\mathrm{N}), 1508 \text { (vC=C, aromatic). }\end{array}$ \\
\hline $3-b$ & 5 & 65 & $165-168$ & Gray crystalline solid & $\begin{array}{l}3240(\mathrm{vN}-\mathrm{H}), 3092 \text { (vC-H,aromatic), 2952\&2865(vC- } \\
\text { H,aliphatic),1599 (vC=N),1600\&1508(vC=C,aromatic). }\end{array}$ \\
\hline 3-c & 5 & 74 & $250-252$ & $\begin{array}{l}\text { Brown } \\
\text { crystalline solid }\end{array}$ & $\begin{array}{l}3240(\mathrm{vN}-\mathrm{H}), 3100(\mathrm{vC}-\mathrm{H}, \text { aromatic), 2924\&2855(vC- } \\
\mathrm{H}, \text { aliphatic),1687 (vC=N),1600\&1500(vC=C, aromatic. }\end{array}$ \\
\hline $3-d$ & 1 & 60 & $210-212$ & Gray crystalline solid & $\begin{array}{l}3240(\mathrm{vN}-\mathrm{H} / \mathrm{OH}), 3092(\mathrm{vC}-\mathrm{H} \text {, aromatic), } 2952 \& 2860(\mathrm{vC}- \\
\mathrm{H} \text {, aliphatic),1599(vC=N),1600\&1500 (vC=C, aromatic). }\end{array}$ \\
\hline
\end{tabular}

the contents melted. The mixture was maintained at melting temperature for $15-20 \mathrm{~min}$. The product obtained on cooling was treated with sodium bicarbonate solution to dissolve the unreacted dicarboxylic acid if any. It was then washed with water and collected by filtration. The product was recrystallised from a mixture of dimethylformamide and water to afford the title compounds 1a-e and characterized spectroscopically. The melting points, yields and IR data of the compounds, 1a-e are given in Table I.

\section{Bis-[4-N-(adamantyl) imino-5-mercapto-1,2,4-triazol-3 -yl] alkanes, $2 a-d$}

A mixture of bis-[4-N-amino-1,2,4-triazol-3-yl] alkanes, 1-a, 1-b, 1-c and 1-e and 2-adamantanone in the ratio of 1:2 in dimethylformamide + ethanol $(5+15 \mathrm{~mL})$ media was heated under reflux on an oil bath for 4-5 hours after the addition of a few drops of concentrated sulfuric acid. The solid mass obtained on cooling the reaction mixture was collected by filtration and recrystallised from dimethylformamide to obtain schiff bases, 2a-d and characterized spectroscopically.

\section{Bis-(6-phenylalanino/tryptopheno/tyrosino-1,2,4- triazolo-[3,4-b]-1,3,4-thiadiazol-4-yl) alkanes, 3a-e}

A three-necked quick fit flask was fitted with a dropping funnel and a condenser. To a mixture of 1 -a/ phenylalanine, 1-e/phenylalanine, 1-e/tryptophan, 1a/tyrosine, 1-d/tyrosine and phosphorus oxychloride was added and the con-tents were heated under reflux for 2 hours on an oil bath. Excess of phosphorus oxychloride was then distilled off and the residue was poured onto crushed ice and stirred well. These were then washed with sodium bicarbonate solution (5\%) and the resulting solids were then washed with water 


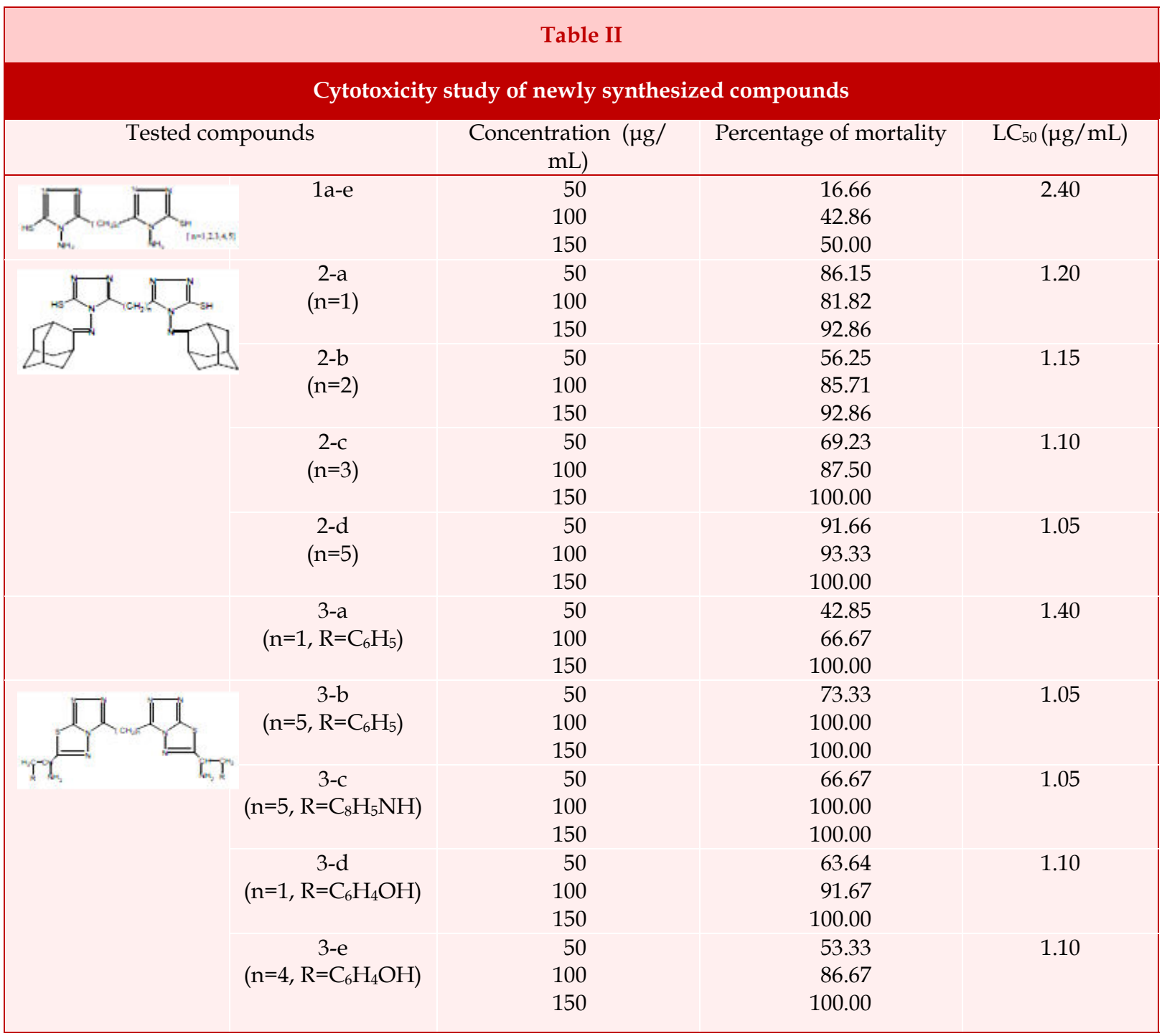

and recrystallised from dimethylformamide to obtain the compounds 3a-e respectively and characterized spectroscopically.

\section{Screening test}

Because of the continuing interest of bis-triazoles derivatives, we conducted cytotoxicity investigation of the newly synthesized compounds by brine shrimp lethality bioassay and the test results show significant activity, as recorded in Table II.

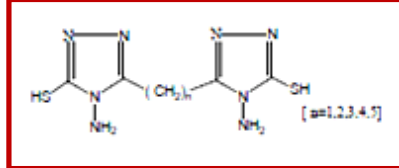

$L C_{50}$

The $\mathrm{LC}_{50}$ of an agent is the concentration, which will kill, or inactive $50 \%$ of the test animal. $\mathrm{LC}_{50}$ is inversely proportional to the toxicity of a compound, i.e. the lower is the $\mathrm{LC}_{50}$, the higher is the cytotoxicity.

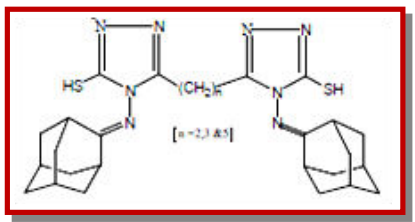

Structural activity relationship (SAR) according to the brine shrimp lethality test

The chemical structure of a drug is important as the relatively minor modification in the drug molecule may result a major change in pharmacological properties. This does not mean that changes in molecular configuration always alter all actions and effects of drug. So we have been able to recognize the functional 


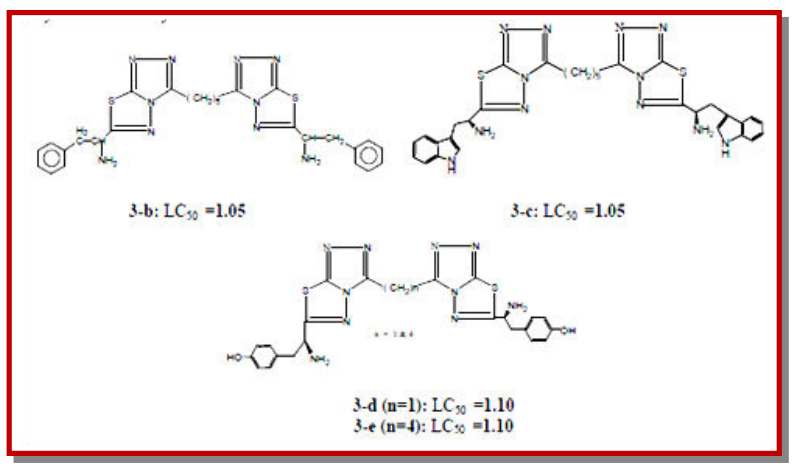

groups/ring and determine which one is important. By synthesizing different compounds, one particular group of the molecule is removed or altered, to find out which groups are essential for biological activity and which are not. In this study we have the following results:

(1) The compounds, 1a-e having free amino $\left(\mathrm{NH}_{2}\right)$ groups showing very little cytotoxic activity.

(2) The schiff bases like 2-b, 2-c and 2-d have very good cytotoxic activity. That is, these compounds may act as potent cytotoxic agents. It should be mentioned here that, as the chain length increases, the cytotoxic activity also increases, i.e., the big molecule can easily interact with the DNA molecule.

(3) The compounds containing amino acid moiety such as, compounds $3 \mathbf{b}$-e have very high cytotoxic activity.

\section{Results and Discussions}

All the newly synthesized compounds analyzed satisfactory for their nitrogen content. Characterization of the compounds was done on the basis of spectral analysis, The IR spectrum of compound 1-b shown absorption bands at 3315 and $3155 \mathrm{~cm}^{-1}$ indicating the presence of primary amino $\left(\mathrm{R}_{-} \mathrm{NH}_{2}\right)$ group in the molecule. The band at $1685 \mathrm{~cm}^{-1}$ indicating the presence of $\mathrm{C}=\mathrm{N}$ in the ring and the band at $2361 \mathrm{~cm}^{-1}$ corresponded the SH functional group in the molecule. In ${ }^{1} \mathrm{H}-\mathrm{NMR}$ spectrum of the compound, 1-b the methylene protons $\left(\mathrm{CH}_{2}\right)$ appear as a singlet at $\delta_{\mathrm{H}} 5.6$, relatively a higher value which may be due to the anisotropic effect of the $\mathrm{C}=\mathrm{N}$ group. The singlet at $\delta_{\mathrm{H}}$ 3.4 arises due to labile protons in $\mathrm{NH}_{2}$. The singlet at $\delta_{\mathrm{H}}$ 2.5 appear due to the proton in SH. In ${ }^{13} \mathrm{C}-\mathrm{NMR}$ spectrum of the synthesized compound 1-b, clearly indicated the three signals at $\delta{ }^{13} \mathrm{C} 21.223,151.2$ and 165.3 corresponded to the nonequivalent carbons respectively.
The IR spectrum of the Schiff base, 2-b did not show any absorption bands corresponding to the $\mathrm{NH}$ stretching frequencies of the parent triazolyl-alakane, 1b. However, a sharp absorption band was seen around $1576 \mathrm{~cm}^{-1}$, corresponding to the $\mathrm{C}=\mathrm{N}$ linkage. The band at $2359 \mathrm{~cm}^{-1}$ corresponded to the $\mathrm{vS}-\mathrm{H}$ stretching. In the ${ }^{1} \mathrm{H}-\mathrm{NMR}$ spectrum, the two labile protons in $\mathrm{SH}$ appeared as a singlet at $\delta_{\mathrm{H}} 3.4$, relatively a higher value which may be due to the electron withdrawing effect of nitrogen atoms (electro-negativity 3.5). The $\mathrm{CH}_{2}$ protons appeared as a triplet at $\delta_{\mathrm{H}} 2.5$ which may be due to the coupling with neighboring $\mathrm{CH}_{2}$ protons. The adamantyl protons appear as multiplets at $\delta_{\mathrm{H}}$ 2.0-1.6. In ${ }^{13} \mathrm{C}-\mathrm{NMR}$ spectrum of the synthesized compound 2-b, clearly indicated the signals at $\delta{ }^{13} \mathrm{C} 20.4,150.2,165.5$ and 161.6 and also $\delta{ }^{13} \mathrm{C} 26-34$ corresponded to the nonequivalent carbons respectively.

In the IR Spectrum of the synthesized com-pounds 3a-e, the absorption band around at $1593 \mathrm{~cm}^{-1}$ come into sight due to the presence of $\mathrm{vC}=\mathrm{N}$ stretching in the ring. At $2360 \mathrm{~cm}^{-1}$ did not show any absorption bands corresponding to the $\mathrm{SH}$ stretching frequencies of the parent triazolylalkanes, 1a-e, confirmed the involvement of the $\mathrm{SH}$ groups of the parent bistriazoles in the cyclisation. In the IR spectra of the cyclised products, 3a-e, the absorption band corresponding to the carbonyl stretching frequency (due to $\mathrm{COOH}$ groups) was absent, which again gave a conclusive evidence for the cyclisation.

In our present research work, the synthesized compounds were investigated for their property as cytotoxic agents by brine shrimp lethality bioassay. Among these compounds 2-b, 2-c, 2-d, 3-b, 3-c, 3-d and 3-e were found to be very active and compounds $2-\mathbf{a}, 3-$ a were moderately active and compounds 1a-e shown very poor activity against brine shrimp.

\section{Financial Support}

Self-funded

\section{Conflict of Interest}

Authors declare no conflict of interest

\section{References}

Andotra CS, Sharma SK. In the synthesis of new 1,3,4oxazdiazole and 1,2,4-triazole derivatives. Indian J Pharm Sci. 1989; 51: 107. 
Heindel ND, Reid JR. 4-Amino-3-mercapto-4H-1,2,4,-triazoles and propargyl aldehydes: A new route to 3-R-8-Aryl-1,2,4triazolo [3,4-b]-1,3,4-thiadiazepines. J Heterocycl Chem. 1980; 17: 1087-88.

Hirota T, Sasaki K, Yamamoto H, Nakayama T. Polycyclic Nhetero compounds. 91XVI. Syntheses and anti-depressive evaluation of 11,13,15,17-tetraazasteroids and their 17oxides. J Heterocycl Chem. 1991; 28: 257-61.

Holla BS, Gonsalves R, Shenoy S. Studies on some N-bridged heterocycles derived from bis-[4-amino-5-mercapto-1,2,4triazol-3-yl]alkanes. Farmaco 1988; 53: 574-78.
Lubrizol Corp, US Pat, 4,246, 126 (1981).

Meyer BN, Ferrigni NR, Putnam JE, Jacobsen LB, Nichols DE, McLaughlin JL. Brine shrimp: A convenient general bioassay for bioactive plant constituents. Planta Med. 1982; 45: 31-34.

Omar AMME, Aboulwafa OM. Synthesis and in vitro antimicrobial and antifungal properties of some novel 1,3,4,thiadiazole and s-triazole $[3,4-\mathrm{b}][1,3,4]$ thiadiazole derivatives. J Heterocycl Chem. 1986; 23: 1339-41.

Yale HL, Piala JJ. Substituted striazoles and related compounds. J Med Chem. 1966; 9: 42-46. 